\title{
PENGARUH KUALITAS LAYANAN DIGITAL, PROMOSI, DAN KEPERCAYAAN TERHADAP KEPUASAN PELANGGAN SHOPEEFOOD
}

\author{
Aldy Ardiansyah, Agus Wahyono*) \\ E-mail: aldy.ardiansyah41@gmail.com, agoeswahyono@gmail.com \\ *) Dosen Tetap FEB USNI Program Studi Manajemen
}

\begin{abstract}
ABSTRACK
This study aims to determine the effect of digital services, promotions, and trust on ShopeeFood customer satisfaction at the University of Satya Negara Indonesia partially or partially. The data used is primary data collected through the distribution of questionnaires to 100 respondents who have installed the ShopeeFood application and used the ShopeeFood application. The method used in this study is a quantitative method and the research results are based on respondents' answers using a Likert scale. The data analysis method used in this research is Multiple Linear Regression Test, $F$ Test, $t$ Test, and Coefficient of Determination.
\end{abstract}

Keywords: Digital Services, Promotion, Trust, Customer Satisfaction.

\section{PENDAHULUAN}

\section{Latar Belakang}

Di masa masa teknologi yang terus menjadi bertambah perdagangan elektronik ataupun yang biasa diucap e- commerce( electronic commerce) ialah bisnis secara elektronik yang menempatkan diri pada transaksi bisnis dengan memakai internet selaku media pertukaran benda serta jasa. Ecommerce sudah menghasilkan suatu kemudahan akses yang relatif terjangkau digolongan warga yang menghubungkan antara industri serta konsumen( Rifai serta Suryani, 2016). Bersama dengan itu e- commerce pula membagikan kenaikan kinerja untuk memudahkan sesuatu sistem data yang menunjang layanan konsumen dalam (Rifai dan Suryani, 2016).

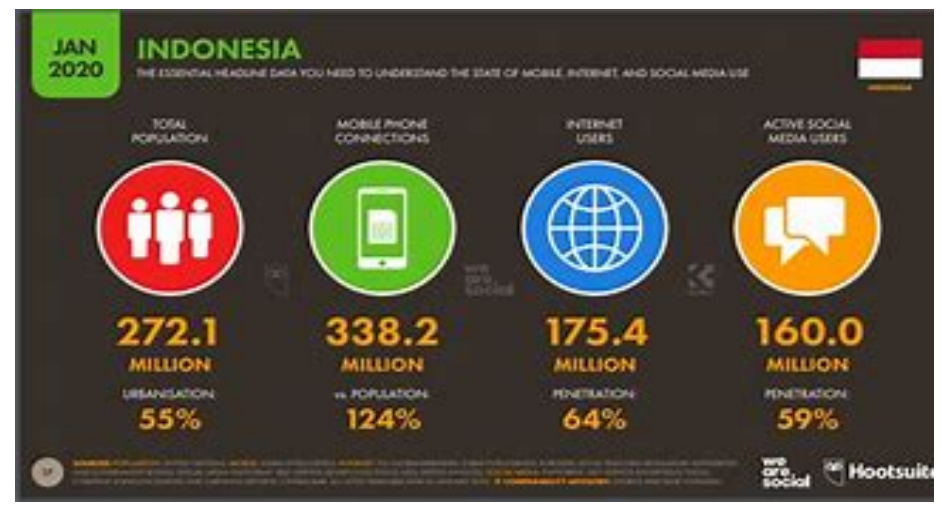

Gambar 1.1. Pengunaan Internet Seluruh Indonesia (Sumber: DetikInet 2020)

Salah satu faktor pendukung dari perkembangan E-commerce di Indonesia adalah semakin meningkatnya penetrasi penggunaan internet di berbagai daerah. Di Indonesia hasil riset menunjukkan pengguna internet mencapai 175.2 juta pengguna. Berdasarkan laporan terbaru We Are Social, pada tahun 2020 disebutkan bahwa ada 175.4 juta pengguna internet di Indonesia. Dibandingkan tahun sebelumnya, ada kenaikan $17 \%$ atau 25 juta pengguna internet di negeri ini. Berdasarkan total populasi Indonesia yang berjumlah 272.1 juta jiwa, maka itu artinya $64 \%$ setengah penduduk RI telah merasakan akses ke dunia maya. Persentase pengguna internet berusia 16 hingga 
64 tahun yang memiliki masing-masing jenis perangkat, di antaranya mobile phone (96\%), smartphone (94\%), non-smartphone mobile phone (21\%), laptop atau komputer desktop $(66 \%)$, tablet $(23 \%)$, konsol game (16\%) hingga virtual reality device $(5.1 \%)$.

Di Indonesia studi menunjukkan saat ini jumlah konsumen digital sudah mencapai 53\% atau setengah dari total populasi Indonesia di tahun 2018 “ $34 \%$ dari orang Indonesia pada tahun 2017 adalah digital consumer. 2018 angka ini menjadi 53\% lebih dari setengah orang yang berusia 15 tahun ke atas telah bertransaksi online" dikutip dari Partner Bain \& Company, Edy Widjaja di The Hermitage. Selain itu, hasil riset mengatakan angka ini diprediksi akan terus bertumbuh hingga beberapa tahun ke depan, berkat bantuan dari akses internet yang semakin meluas. Bahkan pada tahun 2025 mendatang, pertumbuhan belanja online di Indonesia diprediksi tumbuh menjadi USD 48 miliar (Rp 657.7 triliun). Daya beli konsumen Indonesia saat belanja online juga akan melonjak hingga 3.2 kali lipat pada tahun 2025. Jika pada tahun 2018 rata - rata pengeluaran konsumen digital sebesar USD 125 (Rp 1.7 juta), lima tahun lagi angka ini akan mencapai USD 390 (Rp 5.3 juta).

Dari data tersebut sangat cocok untuk melakukan terobosan baru semakin ketatnya persaingan dalam dunia bisnis menuntut setiap perusahaan dapat memiliki keunggulan baik efisien, teknologi, kepuasan konsumen, dan peluang ekspansi usaha serta pangsa pasar komoditi yang kompetitif dan berkesinambungan. Pendatang Baru di Bisnis Pesan - Antar makanan pasar layanan pesan - antar makanan terbukti digandrungi banyak orang, khususnya di masa pembatasan sosial akibat pandemi Covid-19. Berdasarkan penelitian McKinsey pada tahun 2020, terjadi peningkatan sebesar 34\% di Indonesia dalam hal penggunaan jasa pesan antar makanan selama masa pandemi. Survei serupa dari Daily Social and Populix juga mendapatkan data bahwa 53\% responden mengatakan bahwa aplikasi pesan - antar makanan banyak digunakan selama periode karantina mandiri. Global WebIndex melakukan survei global untuk mengetahui apa saja yang membuat orang tergerak untuk memesan makanan secara online, dan lima alasan teratas adalah: gratis ongkos kirim sebanyak 51\%, pengiriman cepat $48 \%$, penawaran diskon $43 \%$, ketersediaan dan kelengkapan produk $36 \%$, serta kemudahan proses pemesanan 30\%. Hal tersebut dapat menciptakan kepuasan pelanggan. Peluang ini dimanfaatkan oleh Shopee melalui kanal Shopee Food sejak April 2020 dengan memasarkan produk makanan dan minuman yang tahan lama seperti frozen food dan minuman kemasan. Saat ini Shopee sedang dalam persiapan untuk semakin memperluas pasar mereka, sekaligus menjadi pesaing layanan pesan-antar makanan yang sudah lebih senior yaitu GoFood dan GrabFood. Bedanya ini adalah kali pertama perusahaan e-commerce bermain di lahan yang lebih dulu dikuasai oleh perusahaan ride hailing. Berikut peesaing Shopee (Shopee Food) dalam jasa layanan antar makanan:

Tabel 1. 1

Tabel Pesaing ShopeeFood

\begin{tabular}{|c|l|c|c|}
\hline No. & Pesaing & $\begin{array}{l}\text { Total Aktivitas } \\
\text { Penjualan }\end{array}$ & Unduhan \\
\hline 1. & Shopee ( ShopeeFood ) & - & $100 \mathrm{jt}+$ \\
\hline 2. & Gojek ( GoFood ) & $47 \%$ & $50 \mathrm{jt}+$ \\
\hline 3. & Grab (GrabFood ) & $53 \%$ & $100 \mathrm{jt}+$ \\
\hline
\end{tabular}

Sumber: katadata.com

Berdasarkan data diatas dapat menunjukkan bahwa GoFood menguasai 47\% senilai sebesar US\$ 1.7 juta, sedangkan GrabFood mendekati US\$ 2 juta atau 53\% dari total aktivitas penjualan. Sementara Shopee (ShopeeFood) belum memiliki total aktivitas penjualan dikarenakan shopeefood baru meluncurkan fitur pesan makanan di platfrom pada bulan April 2020. Sebagai tindak lanjutnya, Shopee pun mulai mencari mitra pengemudi untuk Shopee Food pada November 2020 dan Shopee Food telah memiliki 500 lebih mitra pedagang. Selain itu berdasarkan tabel diatas dapat 
menunjukkan bahwa aplikasi Shopee menguasai peta kompetisi dalam jasa layanan pesan antar makanan dengan unduhan tertinggi di Indonesia, mengungguli pesaing lainnya seperti Grab (GrabFood), dan Gojek (GoFood).

Shopee (ShopeeFood) menjadi pelayanan digital pesan antar makanan, dengan 90\% responden menyatakan Shopee (ShopeeFood) sebagai brand yang banyak digunakan dalam tiga bulan terakhir," kata Head of High Tech, Property \& Consumer Goods Industry MarkPlus, Inc. Rhesa Dwi Prabowo. Selain itu, Shopee juga menjadi e-commerce atau pelayanan jasa antar makanan dengan top of mind atau paling diingat konsumen. Alasan sebuah brand e-commerce dan layanan pesan antar makan dapat membuat pelanggan puas adalah dengan layanan digital yang dapat memudahkan konsumen dalam memesan makanan melalui online. Dalam merilis berbagai rangkaian promosi untuk menarik perhatian konsumen. Shopee menambahkan promosi - promosi tersebut bertujuan memperkuat interaksi dengan konsumen. Interaksi yang kuat nantinya diharapkan membangun kepercayaan dan loyalitas dari konsumen terhadap brand tersebut.

\section{LANDASAN TEORI \\ Kualitas Pelayanan}

Service Quality (Kualitas Pelayanan) merupakan sebuah pondasi dasar bagi pemasaran jasa untuk memperkuat kualitas kinerja, dikarenakan inti produk yang dipasarkan adalah kinerja yang berkualitas dan kinerja itu sendiri yang akan dibeli oleh pelanggan. Service quality (kualitas pelayanan) jauh lebih sukar diartikan, ditafsirkan, dijabarkan, ataupun diukur, dibandingkan dengan kualitas barang. Bila ukuran kualitas dan pengendalian kualitas telah lama dikembangkan dan diterapkan untuk barang berwujud (tangible goods), maka untuk jasa berbagai upaya justru dikembangkan untuk merumuskan ukuran-ukuran semacam itu (Tjiptono, 2014: 266).

\section{Kualitas Layanan Elektronik}

E-Service quality atau yang juga dikenal dengan e-SQ, merupakan pengembangan dari model Service Quality (SERVQUAL). Pada prinsipnya, model $e-S Q$ merupakan adaptasi dan perluasan model tradisional SERVQUAL ke dalam konteks belanja online (Tjiptono, 2014: 303). E-Service Quality yaitu merupakan sebuah kegiatan suatu penilaian dan evaluasi secara menyeluruh atas kualitas layanan kepada konsumen didalam pasar digital (Santos, 2003) dalam (Laurent, 2016). Menurut Voss (2003) E-Service Quality merupakan sebuah pelayanan baru bagi konsumen memfasilitasi dalam lingkungan elektronik (e-service) diartikan sebagai penyerahan jasa dengan media yang lebih canggih dan media baru yaitu web.

\section{Dimensi Kualitas Pelayanan}

Elektronik Parasuraman et. al., (2005) mengidentifikasi terdapat beberapa dimensi dalam kualitas pelayanan elektronik, dimana beberapa dimensi merupakan core (inti) dari kualitas pelayanan elektronik tersebut, yaitu:

a. Efisiensi (Efficiency) Kemudahan dan kecepatan dalam mengakses dan menggunakan situs. Menurut Tjiptono (2014: 303) efisiensi juga mencakup kemampuan pelanggan untuk mengakses website, mencari produk yang diinginkan dan informasi yang berkaitan dengan produk tersebut, dan meninggalkan situs bersangkutan dengan upaya minimal.

b. Pemenuhan Kebutuhan (Fulfillment) Aktual kinerja perusahaan kontras dengan apa yang dijanjikan melalui website. Menurut Tjiptono (2014: 303)fulfillment mencakup akurasi janji layanan, seperti ketersediaan stok produk dan pengiriman produk sesuai dengan waktu yang diinginkan.

c. Ketersediaan Sistem (System Availability) Fungsionalitas sebuah teknik teknologi canggih yang berhubungan, terkait bagian-bagian situs yang tersedia dan dapat berfungsi dengan baik sebagaimana mestinya.

d. Privasi (Privacy) Tingkat dimana situs mampu untuk melindungi informasi pribadi konsumen. Menurut (Tjiptono, 2014: 303) privasi mencakup jaminan data para perilaku 
berbelanja pelanggan yang tidak dibagikan ataupun kebocoran data serta informasi dari kartu kredit pelanggan yang aman terjaga.

\section{Promosi}

Menurut Kotler dan Keller (2016: 219) promosi adalah berbagai cara untuk menginformasikan, membujuk dan menginginkan konsumen secara langsung maupun tidak langsung tentang suatu produk atau brand yang dijual. Menurut Tandjung dalam Tamayani (2015: 247) promosi adalah seni untuk merayu pelanggan dan calon konsumen untuk membeli lebih banyak produk perusahaan.

\section{Dimensi Promosi}

Menurut Kotler dan Keller (2016: 432), dimensi promosi terdiri atas 5 (lima) alat - alat promosi, yaitu:

a. Advertising (periklanan) yaitu "semua bentuk presentasi dan promosi nonpersonal yang dibayar oleh sponsor untuk mempresentasikan gagasan, barang atau jasa". Periklanan dianggap sebagai manajemen citra yang bertujuan menciptakan dan memelihara cipta dan makna dalam benakkonsumen. Bentuk promosi yang digunakan mencakup broadcast, print, internet, outdoor dan bentuk lainnya.

b. Sales promotion (promosi penjualan), yaitu insentif-insentif jangka pendek untuk mendorong pembelian atau penjualan suatu produk atau jasa. Bentuk promosi yang digunakan mencakup discounts, coupons, displays, demonstrations, contests, sweepstakes, dan events.

c. Personal selling (penjualan perseorangan), yaitu presentasi personal oleh tenaga penjualan dengan tujuan menghasilkan penjualan dan membangun hubungan dengan konsumen. Bentuk promosi yang digunakan mencakup presentations, trade shows, dan incentive programs.

d. Public relations (hubungan masyarakat), yaitu membangun hubungan yang baik dengan berbagai publik perusahaan supaya memperoleh publisitas yang menguntungkan, membangun citra perusahaan yang bagus, dan menanganiatau meluruskan rumor, cerita, serta event yang tidak menguntungkan. Bentuk promosi yang digunakan mencakup press releases, sponsorships, special events, dan web pages.

e. Direct marketing (penjualan langsung), yaitu hubungan langsung dengan sasaran konsumen dengan tujuan untuk memperoleh tanggapan segera dan membina hubungan yang abadi dengan konsumen. Bentuk promosi yang digunakan mencakup catalogs.

\section{Kepercayaan (Trust)}

Pengertian Kepercayaan

Kepercayaan (Trust) merupakan elemen dasar pembangunan suatu pondasi dari bisnis. Suatu transaksi bisnis antara kedua belah pihak atau lebih akan terjadi apabila masing-masing saling mempercayai. Kepercayaan (trust) adalah sebuah kunci untuk mendorong hubungan yang kuat dengan konsumen, ini tidak begitu saja dapat langsung diakui oleh pihak lainnya, melainkan harus dibangun mulai dari awal dan dapat dibuktikan. Trust telah dipertimbangkan sebagai perangsang bagi pelanggan didalam sebuah transaksi antara penjual dan pembeli agar kepuasan konsumen dapat terwujud sesuai dengan yang diharapkan (Yousafzai et. al., 2003) dalam penelitian Dicky Kustrianto Fadillah 2017. Hasil identifikasi dari berbagai literatur mengenai kepercayaan (trust) dapat dikemukakan sebagai berikut (Yousafzai et. al., 2003):

Rotter (1967) dalam penelitian Dicky Kustrianto Fadillah 2017 menafsirkan bahwa trust merupakan suatu keyakinan bahwa kata atau janji seseorang dapat dipercaya dan seseorang akan memenuhi kewajibannya dalam sebuah hubungan pertukaran.

Mayer et. al., (1995) dalam penelitian Dicky Kustrianto Fadillah 2017 mengartikan trust adalah kemauan seseorang untuk responsif terhadap suatu tindakan orang lain berdasarkan pada harapan bahwa orang lain akan melakukan tindakan tertentu pada orang yang mempercayainya, tanpa tergantung pada kemampuannya untuk mengawasi dan mengendalikannya. 
Gefen (2000) dalam penelitian Dicky Kustrianto Fadillah 2017 mendefinisikan trust adalah dorongan hati untuk membuat dirinya peka terhadap suatu tindakan yang diambil oleh orang yang dapat dipercayainya didasarkan pada rasa kepercayaan dan tanggung jawab.

Ba dan Pavlou (2002) dalam penelitian Dicky Kustrianto Fadillah 2017mendefinisikan trust adalah sebuah evaluasi penilaian hubungan seseorang dengan pihak lain yang akan melakukan transaksi tertentu menurut harapan orang kepercayaannya dalam suatu lingkungan yang penuh ketidak-pastian.

\section{Dimensi Kepercayaan (Trust)}

Menurut Mayer et. al., (1995) Rofiq dan Mula (2010) dalam penelitian Dicky Kustrianto Fadillah 2017 adapun faktor-faktor yang membentuk suatu kepercayaan seseorang terhadap yang lain ada tiga hal yaitu kemampuan (ability), kebaikan hati (benevolence), dan integritas (integrity). Ketiga faktor tersebut dapat diuraikan sebagai berikut:

a. Kemampuan (Ability)

Kemampuan membentuk pada kompetensi dan karakteristik setiap penjual ataupun organisasi dalam mempengaruhi serta mengkoordinasi wilayah spesifik. .

b. Kebaikan hati (Benevolence)

Kebaikan hati mengutamakan kemauan penjual dalam memperoleh kepuasan yang saling menguntungkan antara dirinya dengan konsumen.

c. Integritas (Integrity)

Integritas berhubungan dengan perilaku atau kebiasaan penjual dalam mewujudkan bisnisnya. Informasi yang diberikan kepada konsumen apakah benar sesuai dengan fakta atau tidak. Kualitas produk yang dijual dapat dipercaya atau tidak. Kim et. al., (2003) dalam penelitian Dicky Kustrianto Fadillah 2017 mengutarakan bahwa integrity dapat dilihat dari sudut pandang kewajaran (fairness), pemenuhan (fulffillment), kesetiaan (loyalty), keterusterangan (honesty), keterkaitan (dependability), dan kehandalan (reliability).

\section{Kepuasan Konsumen (Customer Satisfaction)}

Menurut Lovelock dan Wirtz yang dikutip oleh Fandy Tjiptono (2016:74) kepuasan adalah suatu sikap yang diputuskan berdasarkan pengalaman yang didapatkan. Sangat dibutuhkan penelitian untuk membuktikan ada atau tidaknya harapan sebelumnya yang merupakan bagian terpenting dalam kepuasan.

Sedangkan menurut Tjiptono (2015:146), kepuasan pelanggan adalah perasaan senang atau kecewa seseorang yang muncul setelah membandingkan antara persepsi terhadap kinerja (hasil) suatu produk dengan harapan-harapannya.

Dari keterangan diatas dapat diambil kesimpulan bahwa kepuasan konsumen mencakup perbedaan antara harapan dan kinerja atau hasil yang diharapkan. Jika kinerja yang diterima atau diharapkan melampaui harapan maka akan memuaskan pelanggan. Sebaliknya jika kinerja yang diterima lebih rendah dari yang diharapkan tentu akan mengakibatkan pelanggan tidak puas atas suatu produk atau jasa yang mereka terima.

\section{Kerangka Pemikiran}


Kerangka Penelitian

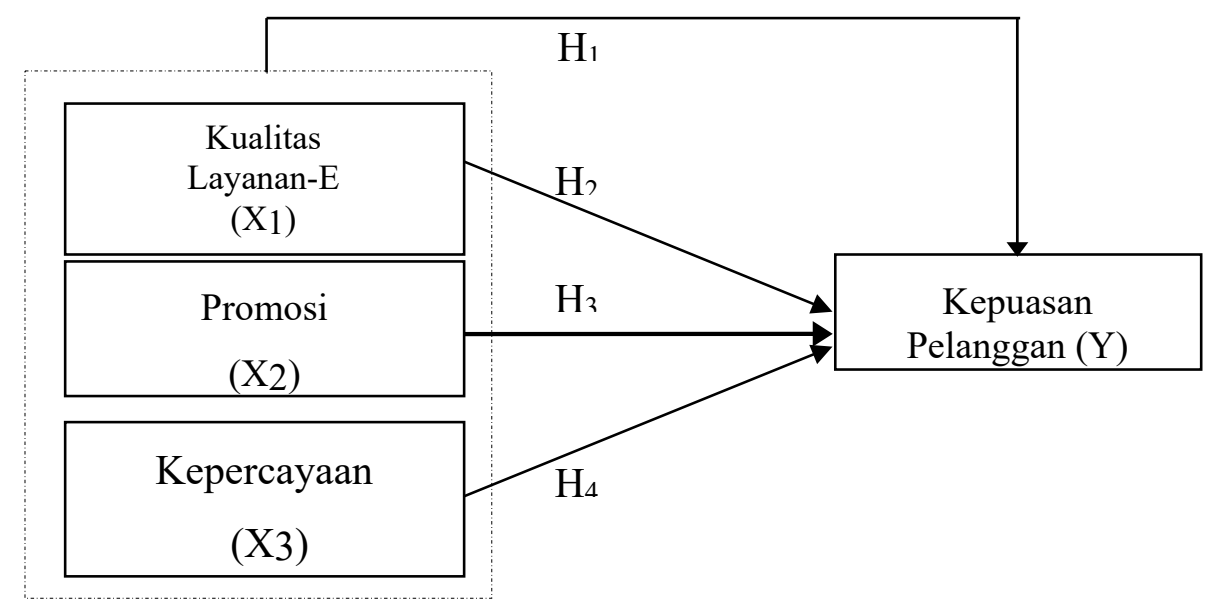

Keterangan :

$\mathrm{X}_{1}$

: Variabel bebas (Kualitas Layanan Digital)

$\mathrm{X}_{2} \quad$ : Variabel bebas (Promosi)

$\mathrm{X}_{3} \quad:$ Variabel bebas (Kepercayaan)

$\mathrm{Y} \quad$ : Kepuasan Pelanggan

Hipotesis Penelitian :

H1: Diduga kualitas layanan digital, promosi dan kepercayaan memiliki pengaruh signifikan secara simultan terhadap kepuasan pelanggan ShopeeFood.

H2 : Diduga kualitas layanan digital memiliki pengaruh signifikan terhadap kepuasan pelanggan ShopeeFood.

H3 : Diduga promosi memiliki pengaruh signifikan terhadap kepuasan pelanggan ShopeeFood.

H4 : Diduga kepercayaan memiliki pengaruh signifikan terhadap kepuasan pelanggan ShopeeFood

\section{Metode Peneliitian}

\section{Lokasi dan Waktu Penelitian}

Dalam penelitian ini, penulis meneliti perilaku pengguna ShopeeFood di Universitas Satya Negara Indonesia Jakarta. Waktu penelitian dilaksanakan pada bulan Maret sampai bulan Juli 2021. Dalam kondisi pandemic seperti ini, penyebaran kuesioner dilakukan dengan metode online dengan menggunakan GoogleForm.

\section{Hasil Penelitian dan Pembahasan}

Tabel 1.1

Output Statistik Deskriptif

\begin{tabular}{|c|c|c|c|c|c|}
\hline \multicolumn{6}{|l|}{ Descriptive Statistics } \\
\hline & $\mathrm{N}$ & Minimum & Maximum & Sum & Mean \\
\hline Kepuasan Pelanggan & 100 & 27 & 45 & 3804 & 38.04 \\
\hline Kualitas Layanan Digital & 100 & 34 & 45 & 3971 & 39.71 \\
\hline Promosi & 100 & 26 & 55 & 4474 & 44.74 \\
\hline Kepercayaan & 100 & 30 & 50 & 4237 & 42.37 \\
\hline Valid N (listwise) & 100 & & & & \\
\hline
\end{tabular}


Berdasarkan tabel 1.2 dapat diketahui bahwa seluruh pernyataan yang diberikan kepada 100 responden pengguna ShopeeFood pada mahasiswa Universitas Satya Negara Indonesia memiliki nilai minimum, maksimum dan mean. Kepuasan pelanggan (Y) mempunyai nilai maksimum 45.00, nilai minimum 27.00 dan mean 38.04. Kualitas pelayanan digital $\left(\mathrm{X}_{1}\right)$ mempunyai nilai maksimum 45.00, nilai minimum 34.00 dan mean 39.07. Promosi $\left(\mathrm{X}_{2}\right)$ mempunyai nilai maksimum 50.00, nilai minimum 30.00 dan mean 42.37. Dan kepercayaan $\left(\mathrm{X}_{3}\right)$ mempunyai nilai maksimum 50.00 nilai minimum 32.00dan mean 42.37 .

Tabel 1.2

Coefficients ${ }^{\mathrm{a}}$

\section{Hasil Uji Multikolonieritas}

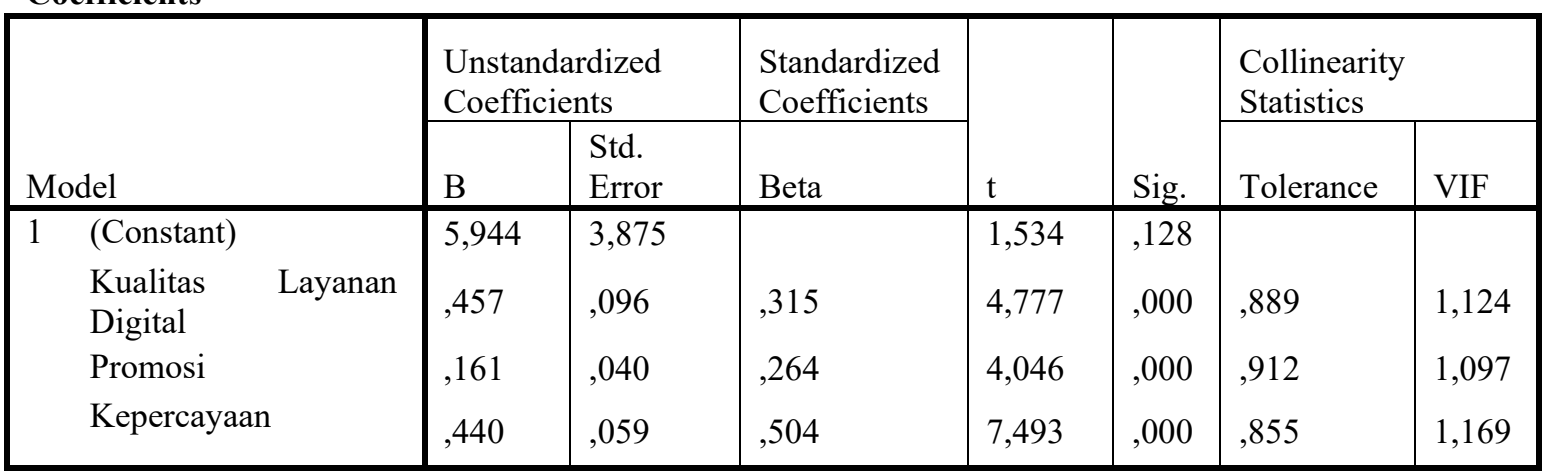

a. Dependent Variable: Kepuasan Pelanggan

Berdasarkan tabel 4.3 diatas terlihat bahwa nilai tolerance mendekati angka 1 dan nilai variance inflation factor (VIF) disekitar angka 1 untuk setiap variabel, yang ditunjukkan dengan nilai tolerance kualitas layanan digital sebesar 0.889 , promosi sebesar 0.912 dan kepercayaan 0.855 . Selain itu nilai VIF untuk kualitas layanan digital sebesar 1.124, promosi 1.097 dan kepercayaan 1.169. Suatu model regresi dikatakan bebas dari problem multiko apabila memiliki nilai VIF kurang dari 10. Dengan demikian, dapat disimpulkan bahwa model persamaan regresi tidak terdapat problem multiko dan dapat digunakan dalam penelitian ini.

Hasil Uji Normalitas - Normal Probability Plot

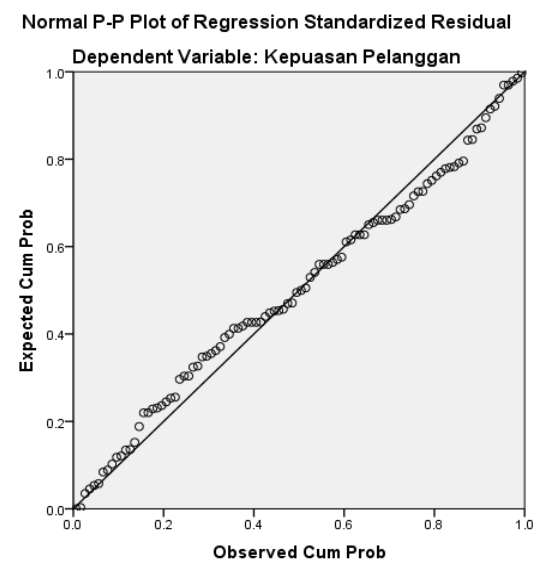

Gambar. 1.3. Hasil Uji Normalitas

Pada gambar 1.3 diatas menunjukkan adanya titik (data) yang tersebar disekitar garis diagonal. Hal ini menunjukkan bahwa model - model regresi dalam penelitian ini dapat memenuhi asumsi normalitas berdasarkan analisis grafik Normal Probability Plot. 
Tabel 1.3

Hasil Uji Normalitas Menggunakan Kolmogorov-Smirn
One-Sample Kolmogorov-Smirnov Test
\begin{tabular}{|ll|l|}
\hline \multicolumn{1}{|l}{} & & $\begin{array}{l}\text { Unstandardized } \\
\text { Residual }\end{array}$ \\
\hline $\mathrm{N}$ & & 100 \\
Normal & Mean &, 0000000 \\
Parameters ${ }^{\mathrm{a}, \mathrm{b}}$ & Std. & 2,48205635 \\
Most Extreme & Absolute &, 071 \\
Differences & Positive &, 071 \\
Test Statistic & Negative &,- 066 \\
Asymp. Sig. (2-tailed) &, 071 \\
\hline
\end{tabular}

a. Test distribution is Normal.

b. Calculated from data.

c. Lilliefors Significance Correction.

d. This is a lower bound of the true significance.

Pada tabel 1.4 uji selanjutnya yang digunakan adalah uji kolmogorov-smirnov, diperoleh hasil output asymp. sig. (2-tailed) sebesar 0.200 atau jauh diatas 0.05 menunjukkan bahwa angka signifikan diatas 0.05 adalah data tersebut terdistribusi secara normal.

Hasil Uji Heteroskedasitas

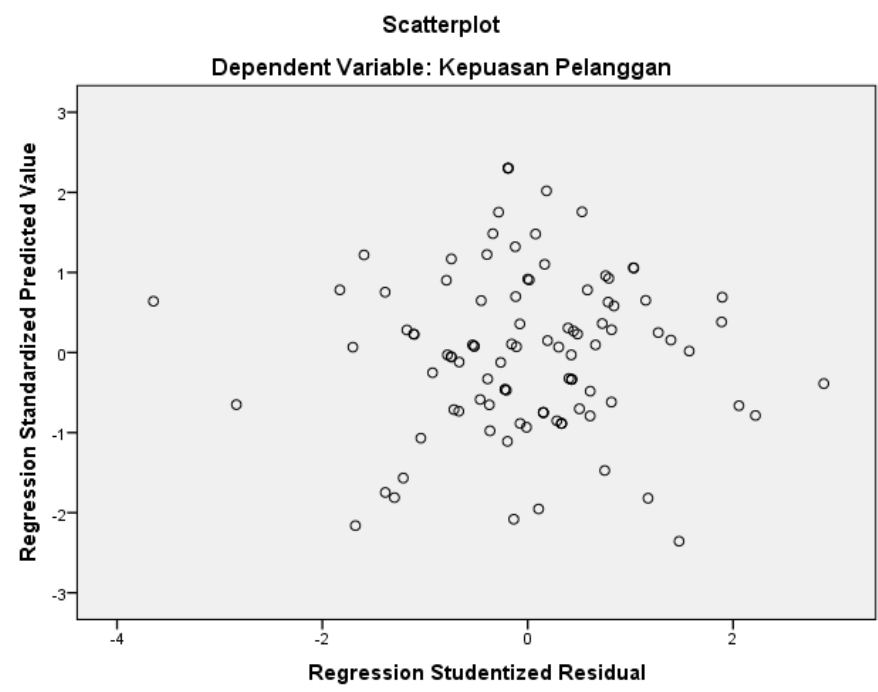

Gambar 1.4

Berdasarkan gambar 1.4 grafik scatterplot menunjukkan bahwa data tersebar di atas dan di bawah angka 0 (nol) pada sumbu Y dan tidak terdapat suatu pola yang jelas pada penyebaran data tersebut. Hal ini berarti tidak terjadi heteroskedastisitas pada model persamaan regresi, sehingga model regresi layak digunakan untuk memprediksi kepuasan pelanggan berdasarkan variabel yang mempengaruhinya, yaitu kualitas layanan digital, promosi dan kepercayaan. 
Tabel 1.4. Hasil Uji Autokorelasi

Model Summary $\mathbf{b}^{\mathbf{b}}$
\begin{tabular}{|l|l|l|l|l|l|}
\hline Model & $\mathrm{R}$ & R Square & $\begin{array}{l}\text { Adjusted } \\
\text { Square }\end{array}$ & $\begin{array}{l}\text { Std. Error of the } \\
\text { Estimate }\end{array}$ & $\begin{array}{l}\text { Durbin- } \\
\text { Watson }\end{array}$ \\
\hline 1 & $.793^{\mathrm{a}}$ & .628 & .616 & 2.521 & 1.770 \\
\hline
\end{tabular}

a. Predictors: (Constant), Kepercayaan, Promosi, Kualitas Layanan Digital

b. Dependent Variable: Kepuasan Pelanggan

Penelitian ini menggunakan Uji Durbin Watson (DW test) sebagai analisis data. Dimana nilai DL dan DU diperoleh dengan melihat tabel statistik Durbin Watson pada tingkat signifikansi $\alpha=5 \%, \mathrm{k}$ $=3$ (jumlah variabel bebas yaitu X1, X2, X3), kemudian diperoleh nilai DL $=1.613$ dan nilai $\mathrm{DU}=$ 1.736 dengan $=100$ (jumlah responden), nilai dari $\mathrm{DW}=2.092$ yang diperolah dari hasil pengolahan data dan 4-DU $=2.264$ dengan SPSS versi 22. Karena nilai Durbin-Waston terletak antara DU $<$ DW $<4$-DU adalah $(1.736<1.770<2.264)$ artinya tidak terjadi autokorelasi.

Tabel 1. 5 Hasil Uji F

ANOVA ${ }^{\mathrm{a}}$

\begin{tabular}{|ll|l|l|l|l|l|}
\hline \multicolumn{2}{|c|}{ Model } & $\begin{array}{l}\text { Sum } \\
\text { Squares }\end{array}$ & of & $\begin{array}{l}\text { Mean } \\
\text { Square }\end{array}$ & F & Sig. \\
\hline 1 & Regression & 1029,940 & 3 & 343,313 & 54,039 & $.000^{\mathrm{b}}$ \\
& Residual & 609,900 & 96 & 6,353 & & \\
\multicolumn{1}{|c|}{ Total } & 1639,840 & 99 & & & \\
\hline
\end{tabular}

a. Dependent Variable: Kepuasan Pelanggan

b. Predictors: (Constant), Kepercayaan, Promosi, Kualitas Layanan Digital

Dari table 1.6 dapat dilihat bahwa $\mathrm{H}_{\mathrm{a}}: \beta_{1}, \beta_{2}, \beta_{3}>0$; terdapat pengaruh secara simultan antara kualitas layanan digital, promosi dan kepercayaan terhadap kepuasan pelanggan. Berdasarkan tabel ANOVA di atas, diperoleh $F_{\text {hitung }}$ sebesar 54.039 dengan tingkat signifikansi sebesar 5\% dan $\mathrm{df}_{1}=3, \mathrm{df}_{2}=96$, didapat nilai $F_{\text {tabel }}=2.70$. Nilai $F_{\text {hitung }}(54.039)>$ nilai $F_{\text {tabel }}(2.70)$ dan tingkat signifikansi hitung $<$ 0.05 maka model regresi dapat digunakan untuk memprediksi kepuasan pelanggan pada pengguna ShopeeFood mahasiswa Universitas Satya Negara Indonesia. Dapat disimpulkan bahwa $\mathrm{H}_{0}$ ditolak dan $\mathrm{H}_{\mathrm{a}}$ diterima. Artinya, variabel- variabel independen yaitu kualitas layanan digital $\left(\mathrm{X}_{1}\right)$, promosi $\left(\mathrm{X}_{2}\right)$, dan kepercayaan $\left(\mathrm{X}_{3}\right)$ berpengaruh secara simultan terhadap variabel dependen kepuasan pelanggan (Y).

\section{Coefficients $^{\mathrm{a}}$}

Tabel 1. 6 Hasil Uji t

\begin{tabular}{|c|c|c|c|c|c|c|c|c|}
\hline & & \multicolumn{2}{|c|}{$\begin{array}{l}\text { Unstandardized } \\
\text { Coefficients }\end{array}$} & \multirow{2}{*}{$\begin{array}{l}\text { Standardized } \\
\text { Coefficients } \\
\text { Beta }\end{array}$} & \multirow[b]{2}{*}{$\mathrm{T}$} & \multirow[b]{2}{*}{ Sig. } & \multicolumn{2}{|c|}{$\begin{array}{l}\text { Collinearity } \\
\text { Statistics }\end{array}$} \\
\hline \multicolumn{2}{|c|}{ Model } & B & $\begin{array}{l}\text { Std. } \\
\text { Error }\end{array}$ & & & & Tolerance & VIF \\
\hline & & 5,944 & 3,875 & & 1,534 & ,128 & & \\
\hline & Layanan &, 457 & ,096 &, 315 & 4,777 & ,000 & ,889 & 1,124 \\
\hline & &, 161 & ,040 & ,264 & 4,046 &, 000 & ,912 & 1,097 \\
\hline & & ,440 &, 059 &, 504 & 7,493 &, 000 &, 855 & 1,169 \\
\hline
\end{tabular}

a. Dependent Variable: Kepuasan Pelanggan

a. Pengaruh Kualitas Layanan Digital Tehadap Kepuasan Pelangan

Karena sig $<\alpha$, maka dapat disimpulkan bahwa $\mathrm{H}_{a 1}$ diterima dan $\mathrm{H}_{0}$ ditolak, artinya variabel 
kualitas layanan digital berpengaruh secara signifikan secara parsial reliability terhadap kepuasan pelanggan.

b. Pengaruh Promosi Terhadap Kepuasan Pelanggan

Karena sig $<\alpha$, maka dapat disimpulkan bahwa $\mathrm{H}_{\mathrm{a} 1}$ diterima dan $\mathrm{H}_{0}$ ditolak, artinya variabel promosi berpengaruh signifikan secara parsial terhadap kepuasan pelanggan.

c. Pengaruh Kepercayaan Terhadap Kepuasan Pelanggan

Karena sig $<\alpha$, maka dapat disimpulkan bahwa $\mathrm{H}_{\mathrm{a} 1}$ diterima dan $\mathrm{H}_{0}$ ditolak, artinya variabel kepercayaan signifikan secara parsial terhadap kepuasan pelanggan.

Tabel 1. 7 Hasil Uji Koefisien Determinasi $\left(\mathbf{R}^{2}\right)$

\begin{tabular}{|c|c|c|c|c|c|}
\hline \multicolumn{6}{|c|}{ Model Summary ${ }^{b}$} \\
\hline Model & $\mathrm{R}$ & R Square & \begin{tabular}{|ll} 
Adjusted & $\mathrm{R}$ \\
Square & \\
\end{tabular} & $\begin{array}{l}\text { Std. Error of the } \\
\text { Estimate }\end{array}$ & $\begin{array}{l}\text { Durbin- } \\
\text { Watson } \\
\end{array}$ \\
\hline 1 & $.793^{\mathrm{a}}$ & .628 & .616 & 2.521 & 1.770 \\
\hline
\end{tabular}

a. Predictors: (Constant), Kepercayaan, Promosi, Kualitas Layanan Digital

b. Dependent Variable: Kepuasan Pelanggan

Tabel 1.8 menunjukkan nilai Adjusted $R$ Square sebesar 0.616 atau 61.6\%, ini menunjukkan bahwa variabel kepuasan pelanggan yang dapat dijelaskan oleh variabel kualitas layanan digital, promosi dan kepercayaan adalah sebesar $61.6 \%$. Sedangkan sisanya sebesar 0.384 atau $38.4 \%$ dipengaruhi variable lain.

Coefficients $^{\mathrm{a}}$

Tabel 4. 8. Hasil Uji Analisis Regresi Berganda

\begin{tabular}{|c|c|c|c|c|c|c|c|}
\hline \multirow[b]{2}{*}{ Model } & \multicolumn{2}{|c|}{$\begin{array}{l}\text { Unstandardized } \\
\text { Coefficients }\end{array}$} & \multirow{2}{*}{$\begin{array}{l}\text { Standardized } \\
\text { Coefficients } \\
\text { Beta }\end{array}$} & \multirow[b]{2}{*}{$\mathrm{T}$} & \multirow[b]{2}{*}{ Sig. } & \multicolumn{2}{|c|}{ Collinearity Statistics } \\
\hline & $\mathrm{B}$ & Std. Error & & & & Tolerance & VIF \\
\hline $1 \quad$ (Constant) & 5,944 & 3,875 & & 1,534 &, 128 & & \\
\hline Kualitas Layanan Digital &, 457 & ,096 & ,315 & 4,777 &, 000 & 889 & 1,124 \\
\hline Promosi &, 161 &, 040 & ,264 & 4,046 &, 000 & ,912 & 1,097 \\
\hline Kepercayaan & ,440 & 059 &, 504 & 7,493 &, 000 &, 855 & 1,169 \\
\hline
\end{tabular}

a. Dependent Variable: Kepuasan Pelanggan

Berdasarkan hasil pengujian diatas, persamaan regresi pengaruh rekrutmen terhadap kinerja pegawai dapat dituliskan kedalam persamaan regresi berikut:

\section{$Y=5.944+0.457 X_{1}+0.161 X_{2}+0.440 X_{3}$}

Nilai konstanta sebesar 5.944 artinya jika kualitas layanan digital $\left(\mathrm{X}_{1}\right)$ promosi $\left(\mathrm{X}_{2}\right)$ dan kepercayaan $\left(\mathrm{X}_{3}\right)$ nilainya adalah 0 , maka kepuasan pelanggan adalah 5.944. koefisien regresi kualitas layanan digital sebesar 0.457 , promosi sebesar 0.161 dan kepercayaan 0.440 mempunyai arti apabila kualitas layanan digital, promosi dan kepercayaan bertambah atau mengalami peningkatan 1 satuan, maka kepuasan pelanggan juga akan mengalami kenaikan.

\section{Pembahasan Dan Interprestasi Hasil Penelitian}

a. Pengaruh Kualitas Layanan Digital $\left(\mathrm{X}_{1}\right)$ Terhadap Kepuasan Pelanggan

Berdasarkan hasil penelitian ini diketahui bahwa kualitas layanan digital $\left(\mathrm{X}_{1}\right)$ yang ada pada pengguna ShopeeFood mahasiswa Universitas Satya Negara berpengaruh signifikan terhadap kepuasan pelanggan (Y). Hal ini dibuktikan dengan $t_{\text {hitung }}>t_{\text {tabel }}(4.777>1.98498)$.

b. Pengaruh Promosi $\left(\mathrm{X}_{2}\right)$ Terhadap Kepuasan Pelanggan $(\mathrm{Y})$

Berdasarkan hasil penelitian ini diketahui bahwa promosi $\left(\mathrm{X}_{2}\right)$ yang ada pada pengguna ShopeeFood mahasiswa Universitas Satya Negara berpengaruh signifikan terhadap 
kepuasan pelanggan $(Y)$. Hal ini dibuktikan dengan $t_{\text {hitung }}>t_{\text {tabel }}(4.046>1.98498)$.

c. Pengaruh Kepercayaan $\left(\mathrm{X}_{3}\right)$ Terhadap Kepuasan Pelanggan $(\mathrm{Y})$

Berdasarkan hasil penelitian ini diketahui bahwa kepercayaan $\left(\mathrm{X}_{3}\right)$ yang ada pada pengguna GrabFood mahasiswa Universitas Satya Negara berpengaruh signifikan terhadap kepuasan pelanggan $(Y)$. Hal ini dibuktikan dengan $t_{\text {hitung }}>t_{\text {tabel }}(7.493>1.98498)$.

d. Pengaruh Kualitas Layanan Digital $\left(\mathrm{X}_{1}\right)$, Promosi $\left(\mathrm{X}_{2}\right)$ Dan Kepercayaan $\left(\mathrm{X}_{3}\right)$ Terhadap Kepuasan Pelanggan

Berdasarkan hasil perhitungan dapat disimpulkan bahwa kualitas layanan digital $\left(\mathrm{X}_{1}\right)$, promosi $\left(\mathrm{X}_{2}\right)$ dan kepercayaan $\left(\mathrm{X}_{3}\right)$ dalam penelitian ini berpengaruh secara positif, bahwa variabel kepuasan pelanggan yang dapat dijelaskan oleh variabel kualitas layanan digital, promosi dan kepercayaan adalah sebesar $61.6 \%$. Sedangkan sisanya sebesar 0.384 atau $38.4 \%$ dipengaruhi variable lain.

\section{Kesimpulan}

Berdasarkan analisis dan pembahasan dari data tentang penilaian responden tentang pengaruh Pengaruh Kualitas Layanan Digital, Promosi, dan Kepercayaan Terhadap Kepuasan Pelanggan ShopeeFood Pada Mahasiswa Universitas Satya Negara Indonesia, maka dapat ditarik kesimpulan, yaitu:

1. Kualitas layanan digital berpengaruh signifikan terhadap kepuasan pelanggan ShopeeFood Pada Mahasiswa Universitas Satya Negara Indonesia.

2. Promosi berpengaruh signifikan terhadap kepuasan pelanggan ShopeeFood Pada Mahasiswa Universitas Satya Negara Indonesia.

3. Kepercayaan berpengaruh signifikan terhadap kepuasan pelanggan ShopeeFood Pada Mahasiswa Universitas Satya Negara Indonesia.

4. Kualitas layanan digital, promosi dan kepercayaan berpengaruh pada kepuasan pelanggan ShopeeFood Pada Mahasiswa Universitas Satya Negara Indonesia

\section{Saran}

Berdasarkan hasil analisis dan kesimpulan diatas, maka ada beberapa saran sebagai berikut:

\section{Untuk Perusahaan}

a. Kualitas Layanan Digital

Peningkatan yang berkelanjutan untuk kualitas layanan digital karena masih adanya responden yang menjawab kurang setuju dengan nilai tertinggi terdapat di pertanyaan: Aplikasi ShopeeFood mudah untuk dioperasikan. Serta peningkatan yang harus dilakukan pihak ShopeeFood adalah kemudahan dan penyederhaan dalam pengoperasian pada aplikasi ShopeeFood, ini dilakukan agar pelanggan lebih efektif dan efisien pada saat melakukan pemesanan pada aplikasi ShopeeFood yang saat ini masih dianggap terlalu banyak pilihan menu aplikasi sehingga mempersulit pelanggan dalam pengoperasain aplikasi ShopeeFood.

b. Promosi

Promosi merupakan satu hal yang sangat penting bagi GrabFood karena untuk meningkatkan penjualan. Dan dapat dilihat dari responden yang menjawab kurang setuju dalam peratanyan diantaranya: Syarat dan ketentuan promosi di aplikasi ShopeeFood jelas. Dalam hal ini yang dilakukan oleh ShopeeFood harus lebih jelas dalam memberikan promo terbaru agar para pelanggan merasa tidak tertipu pada promo yang diberikan oleh pihak ShopeeFood karena saat ini masih banyak pelanggan yang mengaku syarat dan ketentuan promo yang sudah dilakukan namun promo tersebut tidak didapatkan.

c. Kepercayaan

Kepercayaan merupakan satu hal yang sangat penting bagi ShopeeFood karena untuk mendapatkan antusias pelanggan untuk menggunakan aplikasi ShopeeFood. Dan dapat dilihat dari responden yang menjawab netral dalam peratanyan diantaranya: Aplikasi ShopeeFood jujur dalam memberikan promo atau cashback. Dalam hal ini yang dilakukan oleh ShopeeFood harus lebih menjelaskan detail mengenai syarat dan ketentuan untuk promo atau cashback yang diberikan kepada pelanggan agar apa yang menjadi harapan atau 
ekspektasi pelanggan agar para pelanggan merasa puas karena harapan pelanggan sesuai dengan apa yang pelanggan dapatkan dengan menggunakan aplikasi ShopeeFood.

d. Kepuasan Pelanggan

Kepuasan pelanggan merupakan satu hal yang sangat penting bagi organisasi atau perusahaan karena cukup menentukan berlangsungnya sebuah organisasi atau perusahaan adalah kepuasan pelanggan. Dan dapat dilihat dari responden yang menjawab netral dalam peratanyan diantaranya: Pelayanan yang cepat diberikan oleh ShopeeFood saat konsumen membutuhkan bantuan. Dan peningkatan yang dilakukan oleh ShopeeFood harus lebih meningkatkan pelayanan yang cepat ketika pelanggan membutuhkan atau melakukan pengaduan ketika aplikasi atau transakti sedang bermasalah agar tiap pelanggan merasa puas dengan respon yang cepat yang diberikan oleh ShopeeFood.

\section{DAFTAR PUSTAKA}

\section{Sumber Buku dan Jurnal}

Bimo, Edy, dan Srikandi Kumadji. "Pengaruh E-Service Quality dan Perceived Value Terhadap Kepuasaan Pelanggan dan Loyalitas Pelanggan (Survei pada Mahasiswa S1 Universitas Brawijaya yang Melakukan Transaksi Pembelian Online Dengan Mobile Application Tokopedia)", Jurnal Administrasi Bisnis (JAB)|Vol. 38 No.2, 2016

Bimo, Edy, dan Srikandi Kumadji. "Pengaruh E-Service Quality dan Perceived Value Terhadap Kepuasaan Pelanggan dan Loyalitas Pelanggan (Survei pada Mahasiswa S1 Universitas Brawijaya yang Melakukan Transaksi Pembelian Online Dengan Mobile Application Tokopedia)", Jurnal Administrasi Bisnis (JAB)|Vol. 38 No.2, 2016

Cheng, D. S. Y. "An Analysis of Customer Switching Internet Banks in Hong Kong”, The Journal of Global Business Management Volume $8 *$ Number 2. August, 2012.

Dicky, Kustrianto, Fadillah "PENGARUH KUALITAS PELAYANAN ELEKTRONIK, NILAI PELANGGAN, DAN KEPERCAYAAN TERHADAP KEPUASAN KONSUMEN (Studi Kasus Pada Pengguna Layanan Traveloka)" Jurnal UIN 2017

Diza Moniharapon dan Imelda W J Ogi. 2016. Pengaruh Kualitas Pelayanan, Kualitas Produk dan Kepercayaan terhadap Kepuasan Konsumen (Studi pada PT. FIFGroup). Jurnal EMBA Vol 4 No.1.

Ghozali, Imam. "Aplikasi Analisis Multivariate Dengan Program IBM SPSS Edisi Sembilan”, Semarang: Universitas Diponogoro, 2018.

Lasyakka, Bintang. "Faktor-Faktor Kualitas Eservice yang Berpengaruh terhadap Perceived Value pads Website E-Commere Lazada.co.id (Studi Pada Warga Lingkungan Rw.3 Kelurahan Dinoyo Kecamatan Lowokwaru Kota Malang),", Jurnal Administrasi Bisnis

Mayer, R.C., Davis, J. H., dan Schoorman, F. D., (1995), An Integratif Model of Organizational Trust, Academy of Management Review, 30 (3): 709-734.

Morgan, R.M. and Hunt, S.D. (1994), "The commitment-trust theory of relationship marketing", Journal of Marketing, Vol. 58 No. 3, pp. 20-38.

Kotler, Philip \& Amstrong. "Principles of marketing (edisi 14)”, United States of America: Pearson, 2012.

Kotler \& Keller. "Marketing Management”, England: Pearson Education, $2016 .$.

PENGARUH E-SERVICE QUALITY TERHADAP E-SATISFACTION PADA PENGGUNA DI SITUS TOKOPEDIA Anita Tobagus.

PENGARUH E-SERVICE QUALITY DAN E-RECOVERY SERVICE QUALITYTERHADAP ESATISIFACTION SERTA IMPLIKASINYA PADA E-LOYALTY PELANGGAN MASKAPAI PENERBANGAN AIR ASIA Anton Tirta Komara

Priyatno, Duwi. 2014. SPSS 22 Pengolahan Data Terpraktis. CV Andi Offset. Yogyakarta.

Ridho, dan Ignatius. "Analisis Pengaruh E-Service Quality dan Customer Perceived Value Terhadap Kepuasan Pelanggan Serta Dampaknya pada Loyalitas Pelanggan Lovelinks.co.id", 2014.

Rifai, A. dan Suryani, A. (2016). PERAN CUSTOMER PERCEIVED VALUE PADA KEPUASAN 
PELANGGAN TIKET ONLINE. E-Jurnal Manajemen Unud, Vol. 5, No. 6..

Rotter, J.B. (1966), "Generalized expectancies for internal versus external control of reinforcement", Psychological Monographs, Vol. 80, pp. 1-28.

Rousseau, O. M., Sitkin, S. B., et al, 1998. Not So Different After All: A CrossDiscipline View of trust. Academy Of Management Review, vol. 23, pp. 393-404.

Siregar, Syofiyan. 2013. "Metode Penelitian Kuantitatif: Dilengkapi Pebandingan Perhitungan Manual \& SPSS Edisi Pertama”. Jakarta: Kencana Prenamedia Group.

Soewadji, Jusuf. 2012. Pengantar Metodologi Penelitian. Mitra Wacana Media Penerbit. Jakarta.

Sugiyono. "Metode Penelitian Manajemen", Bandung: Alfabeta, 2014.

Sugiyono. "Metode Penelitian Kuantitatif Kualitatif dan R\&D".

Bandung: Alfabeta, 2015.

Turban, King, Lee, Liang, and Turban. "Electronic Commerce A Managerial And Social Networks Perspective, Eighth Edition”, Springer Cham Heidelberg, New York Dordrecht London , 2015.

Yustisi, Suharyono, dan Bafadhal. "Pengaruh E-Service Quality Terhadap Perceived Value dan Ecustomer Satisfaction (Survei Pada Pelanggan Go-Ride Yang Menggunakan Mobile Application Go-Jek Di Kota Malang)”, Jurnal Administrasi Bisnis (JAB)|Vol. 61 No. 1, 2018. 